\title{
Differential Behaviour of Endophilic Anopheles Mosquitoes in Rooms Occupied by Tobacco Smokers and Non-smokers in Two Nigerian Villages
}

\section{1,2,4* OBEMBE, A; ${ }^{2}$ POPOOLA, KOK; ${ }^{3}$ ODUOLA, AO ; ${ }^{4}$ AWOLOLA, ST}

\author{
${ }^{*}$ Department of Biosciences and Biotechnology, Kwara State University Malete, Nigeria \\ ${ }^{2}$ Department of Zoology, University of Ibadan, Ibadan, Nigeria \\ ${ }^{3}$ Department of Zoology, University of Ilorin, Ilorin, Nigeria \\ ${ }^{4}$ Molecular Entomology and Vector Control Research Laboratory, Nigerian Institute of Medical, Research, Yaba, Lagos, Nigeria. \\ *Corresponding Author Email: abiodunobembe@yahoo.com Phone: +234 8064860782
}

\begin{abstract}
The behavioural effect of tobacco smoke on endophilic Anopheles mosquitoes was observed in two North Central Nigerian villages. Pyrethrum spray and exit trap collections of mosquitoes were conducted, between April and November 2014, in two different villages where tobacco smoking was common among the residents. Anopheles mosquito samples collected were identified to sibling species level using species-specific polymerase chain reaction. Presence of human blood in the blood-fed mosquitoes was determined by Enzyme-linked immunosorbent assay. Numbers of mosquitoes collected from the rooms inhabited by tobacco smokers and non-smokers were compared using Student's t-test $(p<0.05)$. At least four times higher exit rates, five times less gravid females and significantly lower numbers of $A n$. gambiae s.1 mosquitoes were found in rooms inhabited by tobacco smokers compared to equal sized rooms occupied by non-smokers in each village. Blood feeding rates $(77-88 \%)$ and human blood indices $(0.82-0.87)$ of mosquitoes were generally high in the habitations of both tobacco smokers and non-smokers. There was predominance of An. gambiae $(\geq$ $86 \%)$ species compared to An. coluzzii $(\leq 14 \%)$ in both villages. Reduced mosquito endophily was observed in the habitations of tobacco smokers compared to the non-smokers. Widespread tobacco smoking habits should be investigated for possible contributions to mosquito behavioural resistance and residual malaria parasite transmission within rural communities.
\end{abstract}

\section{DOI: https://dx.doi.org/10.4314/jasem.v22i6.23}

Copyright: Copyright (c) 2018 Obembe et al. This is an open access article distributed under the Creative Commons Attribution License (CCL), which permits unrestricted use, distribution, and reproduction in any medium, provided the original work is properly cited.

Dates: Received: 11 May 2018; Revised: 25 June: 2018; Accepted: 30 June 2018

Keywords: Anopheles mosquitoes, Tobacco Smoke, Exophily, Malaria

Personal protective measures like the in-house combustions of domestic fuels (Anthony et al., 1992; Bockarie et al., 1994) and repellent plant materials (Seyoum et al., 2002; Moore et al., 2007) have been reported to induce reduced Anopheles mosquito endophily within rural communities. Possible exophilic or irritant effects of other non-targeted human practices on indoor resting mosquitoes should be profiled. Otherwise, such induced exophilic effects shown by low numbers of indoor mosquitoes may be erroneously considered as positive results from an applied intervention or the existence of generally low vector biting densities within a specific community. Here, we report differential Anopheles mosquito exophily found between rooms inhabited by tobacco smoking and non-smoking single-adult-male residents within the same villages in Kwara State, Nigeria.

\section{MATERIALS AND METHODS}

Description of study area: This observation was noticed by serendipity during monthly pyrethrum spray collections (WHO, 2003) of mosquitoes in two different villages; Akorede $\left(\mathrm{N} 08^{\circ} 40.048\right.$ E $004^{\circ}$ $31.370)$ and Lumoh $\left(\mathrm{N} 08^{\circ} 38.001\right.$ E $\left.004^{\circ} 33.740\right)$ located within Moro Local government area of Kwara State, Nigeria. Mud houses (14 in Akorede and 12 in Lumoh) spread across each village had separate kitchens, corrugated iron roofing and no ceilings. Community residents were interviewed during mornings of mosquito collection to confirm the numbers of room occupants and absence of the use of any personal protective measures including bed nets. Male household heads in each village had separate sleeping rooms from other members of the households. Some of the male household heads were observed to smoke cigarettes, with their doors and windows closed, within the early morning hours (6.30 $7.30 \mathrm{am})$. The closed smoke-filled rooms were usually the last to be surveyed in the two different villages because the inhabitants were the last to exit the rooms to allow for mosquito collections. At least $58 \%$ of the singly occupied rooms (14 in Akorede and 12 in Lumoh) had a cigarette smoking male household head as the only occupant. Many of the residents smoked 
cigarettes to stay warm during the cold early mornings experienced in these isolated and largely pristine village environments. Sizes of the singly occupied rooms in each village were measured and only four rooms (two smoke-filled and two smoke-free) were identified as having the same sizes (approximately 3.6 $\mathrm{m}^{2}$ ).

Collection of Sample: During the wet season (April to November 2014), the four rooms identified in each village were surveyed monthly for the presence of endophilic mosquitoes. In addition to the pyrethrum spray collections, seven consecutive days of window exit trap and indoor aspirator mosquito collection were conducted in November. One window exit trap modelled after that of Service (1977) was mounted on a window of each of the selected room at 17:00h the day preceding the start of the collections. Mosquitoes exiting the rooms in both villages were collected from the traps in addition to ten minutes daily hand collections of samples remaining in the rooms using manual aspirators.

Treatment of Sample: Anopheles mosquitoes collected were preserved over desiccated silica gel in labelled Eppendorf tubes. Each Anopheles mosquito was preserved in a separate tube and transported to the Molecular Entomology and Vector Control Research Laboratory of The Nigerian Institute of Medical Research, Lagos.

Analysis of Sample: The female Anopheles mosquitoes collected were identified using the morphological keys of Gillies and Coetzee (1987). Sibling species composition of the identified An. gambiae s.l mosquitoes were determined by species-specific PCR analysis as described by Scott et al. (1993) and Favia et al. (1997). The abdomens of the blood-fed female Anopheles mosquito samples were subjected to human blood meal ELISA following the method of Beier et al. (1988).

Statistical Evaluation of Data: Numbers of female Anopheles mosquitoes collected in the two rooms with and without smoke were transformed $\sqrt{ } \mathrm{n}+0.5$ (Ogbeibu, 2005) to attain normal distribution and compared using student t-test $(p<0.05)$. Exit rates of female An. gambiae s.l mosquitoes from the selected rooms in the two villages were determined as numbers of mosquitoes found in exit traps divided by the total numbers of mosquitoes found in both rooms and traps (WHO, 2006).

\section{RESULTS AND DISCUSSION}

Numbers of female An. gambiae s.l mosquitoes collected in different rooms and results of the statistical comparisons within each of the village are presented in Tables 1 and 2 respectively. In Akorede $(t=-8.24, \mathrm{df}=7, p<0.001)$ and Lumoh $(t=-5.64, \mathrm{df}=7$, $p=0.001)$ villages, the mean numbers of female mosquitoes in the two rooms with smoke were significantly lower than in the two rooms without smoke (Figure 1). In contrast, there were no significant differences ( $p \geq 0.769)$ between the number of mosquitoes in the first and second rooms without smoke and between first and second rooms with smoke within each village (Table 2). Results of single room comparisons showed significantly $(p \leq 0.007)$ lower numbers of mosquitoes in each of the smoke filled rooms compared to either of the two rooms without smoke within the same village (Table 2). Total numbers of female Anopheles caught in the exit traps of the smoke-filled rooms in Akorede (68) and Lumoh (52) were respectively higher than those resting indoors $(11,15)$ in the villages. In the rooms with no smoke, numbers of mosquitoes in the exit traps (Akorede 19, Lumoh 14) were lower than the numbers (Akorede 82, Lumoh 50) found indoors. Exit rates of female Anopheles mosquitoes from the smoke-filled rooms in both villages (Akorede 0.86, Lumoh 0.78) were higher (4.5 and 3.6 times) compared to the rooms with no smoke (Akorede 0.19, Lumoh 0.22) (Figure 2). There were higher proportions of gravid mosquitoes in the rooms with no smoke (Akorede 9.3\%, Lumoh $10.2 \%$ ) compared to the smoke-filled (Akorede 0\%, Lumoh 1.9\%) rooms. Apart from every part of the rooms being covered with smoke in the mornings, the cigarette type, numbers of sticks lighted, possibility of evening smoking habit, and the level of smoke expelled in the smoke-filled rooms in both villages were not measured. Nevertheless, the results of at least 4 times higher exit rates, 5 times less gravid females and significantly lower numbers of mosquitoes suggest increased exophily among the mosquitoes in the smoke-filled rooms compared to the rooms with no smoke. Since the properties of the tobacco smoke were not assessed for irritant effect, the induced exophily observed could only be attributed to reduced humidity caused by heat. Therefore, in situations where indoor tobacco smoking habit is widespread among residents of rural communities, contributions of the smoke to mosquito exophily and residual malaria parasite transmission should be investigated. While there are no previous reports on the effect of tobacco smoke on mosquitoes, some reports have shown that wood smoke from domestic fuel-use deterred mosquitoes from resting or hibernating in houses (Kligler and Mer, 1932; Barber and Forbich, 1933). 


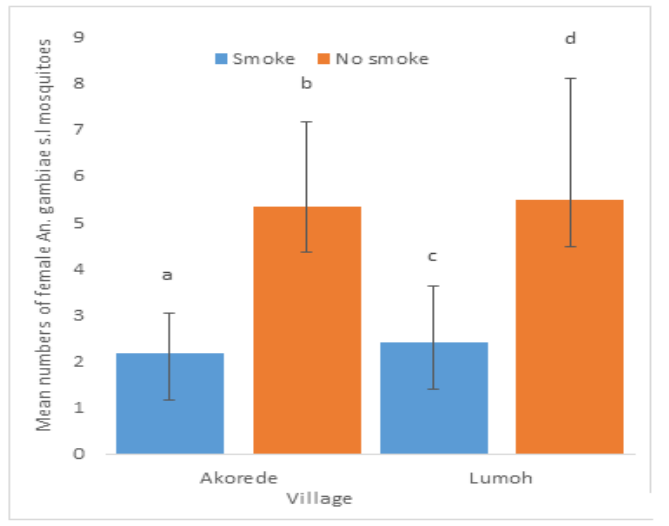

Fig 1: Mean $( \pm \mathrm{SE})$ numbers of female An. gambiae s.1 mosquitoes collected by pyrethrum spray catches in both villages for the eight month period.

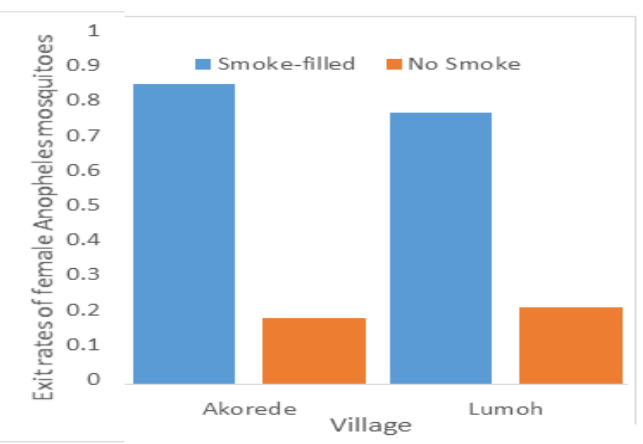

Fig 2: Exit rates of female An. gambiae s.l mosquitoes from the two categories of rooms in both villages
Blood feeding rates of mosquitoes were generally high (77-88\%). The least percentage values were observed among samples collected from exit traps mounted in rooms with no smoke (77\%) and smoke-filled rooms $(82 \%)$ in Akorede village.

Exit traps in Lumoh village had $83 \%$ blood-fed mosquitoes from rooms with no smoke and $88 \%$ blood-fed samples from the smoke-filled rooms. As for the mosquitoes collected indoors, percentage blood feeding rates of An. gambiae s.l mosquitoes in rooms with and without smoke were $83.0 \%$ and $86.3 \%$ in Lumoh and $89.7 \%$ and $85.8 \%$ in Akorede village respectively. High blood feeding rates $(\geq 77 \%)$ of mosquitoes collected from the smoke-filled rooms is expected since the time of tobacco smoking is not likely to coincide with mosquito late night and early morning peak biting times.

This result agrees with the reports of similar studies (Snow et al., 1987; Lindsay and Janneh, 1989; Bockarie et al., 1994) demonstrating the inability of wood smoke to prevent endophagy of Anopheles mosquitoes in rural communities. Human blood indices of all the mosquitoes (spray-catch and exit traps) were high in both Akorede (0.87) and Lumoh (0.82) villages. This is attributable to the strong anthropophilic nature of the An. gambiae mosquito species as reported in earlier studies (Pates and Curtis, 2005; Lyimo and Ferguson, 2009).

Table 1: Numbers of female An. gambiae s.l in rooms with and without tobacco smoke in the villages.

\begin{tabular}{|c|c|c|c|c|c|c|c|}
\hline \multirow[t]{3}{*}{ Village } & \multirow[t]{3}{*}{ Month } & \multicolumn{3}{|c|}{ Smoked filled rooms } & \multicolumn{3}{|c|}{ Rooms without smoke } \\
\hline & & \multicolumn{3}{|c|}{ Actual (transformed) no of Anopheles } & \multicolumn{3}{|c|}{ Actual (transformed) no of Anopheles } \\
\hline & & Room one & Room two & Total & Room one & Room two & Total \\
\hline \multirow{8}{*}{ Akorede } & April & $5(2.35)$ & $4(2.12)$ & $9(3.08)$ & $22(4.74)$ & $23(4.85)$ & $45(6.75)$ \\
\hline & May & $2(1.58)$ & $1(1.22)$ & $3(1.87)$ & $10(3.24)$ & $6(2.55)$ & $16(4.06)$ \\
\hline & June & $0(0.71)$ & $1(1.22)$ & $1(1.22)$ & $6(2.55)$ & $9(3.08)$ & $15(3.94)$ \\
\hline & July & $0(0.71)$ & $1(1.22)$ & $1(1.22)$ & $4(2.12)$ & $4(2.12)$ & $8(2.92)$ \\
\hline & Aug & $1(1.22)$ & $0(0.71)$ & $1(1.22)$ & $9(3.08)$ & $11(3.39)$ & $20(4.53)$ \\
\hline & Sep & $2(1.58)$ & $7(2.74)$ & $9(3.08)$ & $34(5.87)$ & $36(6.04)$ & $70(8.39)$ \\
\hline & Oct & $6(2.55)$ & $4(2.12)$ & $10(3.24)$ & $25(5.05)$ & $20(4.53)$ & $45(6.75)$ \\
\hline & Nov & $4(2.12)$ & $1(1.22)$ & $5(2.35)$ & $15(3.94)$ & $13(3.67)$ & $28(5.34)$ \\
\hline Mean \pm S.D ${ }^{\dagger}$ & & $\left(1.60 \pm 0.70^{a}\right)$ & $\left(1.57 \pm 0.68^{a}\right)$ & $\left(2.16 \pm 0.89^{c}\right)$ & $\left(3.82 \pm 1.31^{\mathrm{b}}\right)$ & $\left(3.78 \pm 1.29^{\mathrm{b}}\right)$ & $\left(5.34 \pm 1.83^{\mathrm{d}}\right)$ \\
\hline \multirow[t]{6}{*}{ Village } & \multirow[t]{3}{*}{ Month } & \multicolumn{3}{|c|}{ Smoked filled rooms } & \multicolumn{3}{|c|}{ Rooms without smoke } \\
\hline & & \multicolumn{3}{|c|}{ Actual (transformed) no of Anopheles } & \multicolumn{3}{|c|}{ Actual (transformed) no of Anopheles } \\
\hline & & Room one & Room two & Total & Room one & Room two & Total \\
\hline & April & $2(1.58)$ & $3(1.87)$ & $5(2.35)$ & $14(3.81)$ & $32(5.70)$ & $46(6.82)$ \\
\hline & May & $0(0.71)$ & $2(1.58)$ & $2(1.58)$ & $9(3.08)$ & $3(1.87)$ & $12(3.54)$ \\
\hline & June & $1(1.22)$ & $0(0.71)$ & $1(1.22)$ & $3(1.87)$ & $8(2.92)$ & 11(3.39) \\
\hline \multirow[t]{5}{*}{ Lumoh } & July & $3(1.87)$ & $0(0.71)$ & $3(1.87)$ & $6(2.55)$ & $3(1.87)$ & $9(3.08)$ \\
\hline & Aug & $1(1.22)$ & $2(1.58)$ & $3(1.87)$ & $8(2.92)$ & $4(2.12)$ & $12(3.54)$ \\
\hline & Sep & $10(3.24)$ & $11(3.39)$ & $21(4.64)$ & $40(6.36)$ & $56(7.52)$ & $96(9.82)$ \\
\hline & Oct & $10(3.24)$ & $5(2.35)$ & $15(3.87)$ & $40(6.36)$ & $33(5.79)$ & $73(8.57)$ \\
\hline & Nov & $0(0.71)$ & $3(1.87)$ & $3(1.87)$ & $17(4.18)$ & $8(2.92)$ & $25(5.05)$ \\
\hline Mean \pm S.D ${ }^{\dagger}$ & & $\left(1.72 \pm 1.01^{\mathrm{a}}\right)$ & $\left(1.76 \pm 0.87^{\mathrm{a}}\right)$ & $\left(2.41 \pm 1.20^{c}\right)$ & $\left(3.89 \pm 1.68^{\mathrm{b}}\right)$ & $\left(3.84 \pm 2.18^{\mathrm{b}}\right)$ & $\left(5.48 \pm 2.62^{\mathrm{d}}\right)$ \\
\hline
\end{tabular}


Table 2: Statistical comparisons of numbers of female An. gambiae s.1 mosquitoes collected within each village

\begin{tabular}{|c|c|c|}
\hline \multicolumn{3}{|l|}{ Akorede } \\
\hline \multicolumn{3}{|c|}{$\begin{array}{l}\text { Points of mosquito collection and mean } \\
\text { numbers of female Anopheles collected }\end{array}$} \\
\hline \multirow{4}{*}{$\begin{array}{l}\text { Smoke room one } \\
1.60 \pm 0.70\end{array}$} & & $p$ \\
\hline & No smoke room one & $<0.001$ \\
\hline & $3.82 \pm 1.31$ & \\
\hline & No smoke room two & $<0.001$ \\
\hline \multirow{3}{*}{$\begin{array}{l}\text { Smoke room two } \\
1.57 \pm 0.68\end{array}$} & No smoke room one & $<0.001$ \\
\hline & $3.82 \pm 1.31$ & \\
\hline & $\begin{array}{l}\text { No smoke room two } \\
3.78 \pm 1.29\end{array}$ & $<0.001$ \\
\hline \multirow{4}{*}{$\begin{array}{l}\text { No smoke room } \\
\text { one } \\
3.82 \pm 1.31 \\
\text { Smoke room one } \\
1.60 \pm 0.70\end{array}$} & No smoke room two & 0.769 \\
\hline & $3.78 \pm 1.29$ & \\
\hline & Smoke room two & 0.901 \\
\hline & $1.57 \pm 0.68$ & \\
\hline \multirow{2}{*}{$\begin{array}{l}\text { Total (smoke } \\
\text { rooms) } \\
2.16 \pm 0.89\end{array}$} & $\begin{array}{l}\text { Total (no smoke } \\
\text { rooms) }\end{array}$ & $<0.001$ \\
\hline & $5.34 \pm 1 . .83$ & \\
\hline
\end{tabular}

There was preponderance of An. gambiae; $91 \%$ of 503 mosquitoes in Akorede and $86 \%$ of 473 total mosquitoes in Lumoh respectively, compared to $A n$. coluzzii. Awolola et al. (2005) had earlier observed that An. gambiae species had higher incidence in the Savannah compared to Forest regions of Nigeria. The site of this study (Kwara State) is in the Guinea Savannah and therefore conformed to this trend. Earlier report from rural communities in Kwara state have also shown the predominance of An. gambiae over An. coluzzii (Oduola et al., 2016).

Acknowledgement: Residents of the two villages are gratefully acknowledged for their cooperation all through the period of this study.

Research Ethical Issues: Informed consent was sought and obtained from the community and household heads before the collection of mosquitoes in the rooms within the community. Ethical approval for the study was obtained from the Ethical Review Board of The Nigerian Institute of Medical Research.

Conflict of interest: The authors declare that they have no competing interests.

Conclusion: This study gives a first report on the exophilic effect of residents' tobacco smoking habits on indoor resting Anopheles mosquitoes in rural communities. The results highlight the need to investigate the contribution of tobacco smoke to Anopheles mosquito exophily and residual malaria parasite transmission in rural communities with widespread tobacco smoking residents.

\begin{tabular}{|c|c|c|}
\hline \multicolumn{3}{|l|}{ Lumoh } \\
\hline \multicolumn{3}{|c|}{$\begin{array}{l}\text { Points of mosquito collection and mean } \\
\text { numbers of female Anopheles collected }\end{array}$} \\
\hline \multirow{3}{*}{$\begin{array}{l}\text { Smoke room one } \\
1.72 \pm 1.01\end{array}$} & & $p$ \\
\hline & $\begin{array}{l}\text { No smoke room one } \\
3.89 \pm 1.68\end{array}$ & $<0.001$ \\
\hline & $\begin{array}{l}\text { No smoke room two } \\
3.84 \pm 2.18\end{array}$ & 0.005 \\
\hline \multirow[t]{2}{*}{$\begin{array}{l}\text { Smoke room two } \\
1.76 \pm 0.87\end{array}$} & $\begin{array}{l}\text { No smoke room one } \\
3.89 \pm 1.68\end{array}$ & $<0.001$ \\
\hline & $\begin{array}{l}\text { No smoke room two } \\
3.84 \pm 2.18\end{array}$ & 0.007 \\
\hline \multirow{2}{*}{$\begin{array}{l}\text { No smoke room } \\
\text { one } \\
3.89 \pm 1.68 \\
\text { Smoke room one } \\
1.72 \pm 1.01\end{array}$} & $\begin{array}{l}\text { No smoke room two } \\
3.84 \pm 2.18\end{array}$ & 0.907 \\
\hline & $\begin{array}{l}\text { Smoke room two } \\
1.76 \pm 0.87\end{array}$ & 0.911 \\
\hline $\begin{array}{l}\text { Total } \quad \text { (smoke } \\
\text { rooms) }\end{array}$ & $\begin{array}{l}\text { Total (no smoke } \\
\text { rooms) }\end{array}$ & $<0.001$ \\
\hline $2.41 \pm 1.20$ & $5.48 \pm 2.62$ & \\
\hline
\end{tabular}

\section{REFERENCES}

Anthony, RL; Bangs, MJ; Hamzah, N; Purnomo, BH; Subianto B (1992). Heightened transmission of stable malaria in an isolated population in the highlands of Irian Jaya, Indonesia. Am J Trop Med Hyg 47: 346-365

Bockarie, MJ; Service, MW; Barnish, G; Momoh, W; Salia, F (1994). The effect of woodsmoke on the feeding and resting behaviour of Anopheles gambiae s.s. Acta Trop 57: 337-340.

Seyoum, A; Pålsson, K; Kung'a, S; Kabiru, EW; Lwande, W; Killeen, GF; Hassanali, A; Knols, BG (2002). Traditional use of mosquito-repellent plants in western Kenya and their evaluation in semi-field experimental huts against Anopheles gambiae: ethnobotanical studies and application by thermal expulsion and direct burning. Trans $R$ Soc Trop Med Hyg 96:225-231.

Moore, SJ; Cameron, MM; Hill, N (2007). Field evaluation of traditionally-used plant-based insect repellents and fumigants against the malaria vector Anopheles darlingi in Riberalta, the Bolivian Amazon. J Med Entomol 44:624-630.

WHO (2003). Malaria entomology and vector control: Learner's guide. World Health Organization. Geneva. Switzerland. 2003; Available: http://whqlibdoc.who.int/hq/2003/WHO_CDS_CPE_SMT_2002.18_Rev.1_PartI.pdf

Service, MW (1977). A critical review of procedures for sampling populations of adult mosquitoes. Bull Entomol Res 67: 343-382. 
Gillies, MT; Coetzee, MA (1987). Supplement to the Anophelinae of Africa South of the Sahara (Afrotropical region). Pub South Afri Inst Med Res 55: 141-143.

Scott, JA; Brogdon, WG; Collins, FH (1993). Identification of single specimens of the $A n$. gambiae complex by the polymerase chain reaction. Am J Trop Med Hyg 49: 520-529.

Favia, G; della Torre, A; Bagayoko, M; Lanfrancotti, A; Sagnon, N; Toure, YT; Coluzzi, M (1997). Molecular identification of sympatric chromosomal forms of Anopheles gambiae and further evidence of their reproductive isolation. Insect Mol Biol 6: 377-383.

Beier, JC; Perkins, PV; Wirtz, RA; Oros, J; Diggs, D; Gargan, TP $2^{\text {nd }}$; Koech, DK (1988). Blood meal identification by direct enzyme-linked Immunosorbent assay (ELISA), tested on Anopheles (Diptera: Culicidae) in Kenya. J Med Entomol 25: 9-16.

Ogbeibu, AE (2005) Biostatistics: A practical approach to research and data handling. Mindex Publishing Company Limited, Benin City. 131 p.

WHO (2006). Guidelines for testing mosquito adulticides for indoor residual spraying and mosquito net treatment. Available: whqlibdoc.who.int/.../2006/WHO_CDS_NTD_ WHOPES_GCDPP_2006.

Kligler, IJ; Mer, G (1932). Studies on malaria in an uncontrolled hyperendemic area. X.-behaviour of A. eletus in relation to housing and malaria. IRiv Di Malariologia 11:553-583.
Barber, MA; Forbrich, LR (1933). Malaria in the irrigated regions of New Mexico. Pub Hlth Rep 48: 610-623.

Pates, H; Curtis, C (2005). Mosquito behaviour and vector control. Annu Rev Entomol 50:53-70.

Lyimo, IN; Ferguson, HM (2009). Ecological and evolutionary determinants of host species choice in mosquito vectors. Trends Parasitol 25:189196.

Snow, RW; Bradley, AK; Hayes, R; Byass, P; Greenwood, BM (1987). Does wood smoke protect against malaria? Ann Trop Med Parasitol 81: 449-451.

Lindsay, SW; Janneh, LM (1989). Preliminary field trials of personal protection against mosquitoes in The Gambia using DEET or permethrin soap, compared with other methods. Med Vet Entomol 3: $97-100$.

Awolola, TS; Oyewole, IO; Amajoh CN; Idowu, ET; Ajayi, MB; Oduola, AO; Manafa, OU; Ibrahim, K; Koekemoer, LL; Coetzee, M (2005). Distribution of the molecular forms of Anopheles gambiae and pyrethroid knock down resistance gene in Nigeria. Acta Tropica 95: 204-209.

Oduola, AO; Adelaja, OJ; Aiyegbusi, ZO; Monday, T; Obembe, A; Ande, AT; Awolola, TS (2016). Dynamics of Anopheline vector species composition and reported malaria cases during the rain and dry season in two selected communities in Kwara state. Nigerian J Parasitol 37(2): 158164. 